\title{
Análise de redes sociais: uma proposta metodológica para a pesquisa em saúde e na enfermagem
}

\author{
Social network analysis: a research methodology for health and nursing
}

Análisis de redes sociales: una propuesta metodológica para la investigación en salud y en la enfermería

\author{
Deyvyd Manoel Condé Andrade'; Helena Maria Scherlowski Leal David"I
}

\begin{abstract}
RESUMO: A metodologia de análise de redes sociais é uma proposta de estudo que analisa as estruturas sociais, suas interações e redes sociais. A partir de sociogramas e indicadores, é possível fazer uma análise quantitativa e qualitativa do modo como ocorrem as interações, a mediação do conhecimento e o fluxo da informação. O presente artigo teve como objetivo apresentar a análise de redes sociais como uma proposta de metodologia de pesquisa em saúde e na enfermagem, pontuando conceitos e trazendo alguns possíveis exemplos de aplicação dessa metodologia. Essa metodologia possibilita às políticas públicas em saúde uma real dimensão das interações entre profissionais de saúde, gestores e usuários, trazendo ao planejamento em saúde e na enfermagem novas ações que, muitas vezes, não estão contidas em tais políticas e não abarcam a realidade vivenciada pelos atores sociais. Palavras-Chave: Metodologia; enfermagem; análise de rede social; saúde.
\end{abstract}

ABSTRACT: Social network analysis is a methodological proposal for analyzing social structures, their interactions and social networks. From sociograms and indicators, it can be determined quantitatively and qualitatively how interactions occur, knowledge is mediated and information flows. This article presenting social network analysis as a methodology for research in health and nursing, highlights concepts and offers some possible examples of its application. By affording public health policaymaking access to the real dimensions of interactions among health professionals, managers and users, the methodology brings health care and nursing planning to consider new actions often omitted from such policies, which fail to contemplate the real situation of the social actors involved. Keywords: Methodology; nursing; social network analysis; health.

RESUMEN: La metodología de análisis de redes sociales es una propuesta para un estudio de análisis de las estructuras sociales, sus interacciones y redes sociales. A partir de sociogramas e indicadores, es posible hacer un análisis cuantitativo y cualitativo de cómo se producen las interacciones, la mediación del conocimiento y el flujo de información. Este artículo tiene como objetivo presentar el análisis de las redes sociales como una propuesta de metodología de investigación en salud y en enfermería, trayendo conceptos y algunos posibles ejemplos de aplicación de esta metodología. Esta metodología les permite a las políticas públicas de salud una dimensión real de las interacciones entre los profesionales de la salud, gestores y usuarios, contribuyendo para la planificación en salud y enfermería con nuevas acciones que, a menudo, no están incluidas en estas políticas y no abarcan la realidad vivida por los actores sociales.

Palabras Clave: Metodología; enfermería; análisis de redes sociales; salud.

\section{INTRODUÇÃO}

As redes sociais vêm se apresentando, nos dias de hoje, como um conceito onipresente, ocupando discurso crescente no meio acadêmico, nas mídias, nos variados tipos de organizações e no senso comum ${ }^{1}$. Essas redes estão conectadas por relacionamentos/ interações sociais que podem ser motivadas por amizade e por relações de trabalho ou compartilhamento de informações nas quais, por meio dessas ligações, a estrutura social vai se (re)construindo 2 .

Importante destacar que o conceito de capital social se faz presente, sendo fundamental para a construção das redes sociais. Estas são construídas a partir de um capital social em constante movimento, constituídas a partir de relações vinculadas a um grupo de agentes que não são apenas dotados de propriedades comuns, mas unidos por ligações permanentes e úteis. Estas ligações não se reduzem às relações de proximidade, em termos de espaço geográfico ou no espaço econômico e social em que estão submetidos. Elas, por exemplo, ocorrem a partir de trocas materiais e simbólicas inseparáveis, permitindo a instauração e perpetuação do (re)conhecimento dessa proximidade 3 .

\footnotetext{
IMestre em Enfermagem. Secretaria Municipal de Saúde de Leopoldina. Leopoldina, Minas Gerais, Brasil. E-mail:E-mail: dvdmcaenf@gmail.com. IIDoutora em Saúde Pública. Professora Associada do Programa de Pós-Graduação em Enfermagem da Faculdade de Enfermagem da Universidade do Estado do Rio de Janeiro. Brasil. E-mail: helenalealdavid@gmail.com.
} 
O capital social pode ser entendido como a totalidade de recursos decorrentes de uma rede de relações de reconhecimento mútuo demarcados em campos sociais. Esses recursos são empregados pelos agentes por meio de uma estratégia de progresso dentro da hierarquia social do campo, prática que resulta da interação do indivíduo com a estrutura e vice-versa. Cada campo pode ser caracterizado como espaço de manifestação de relações de poder; assim, esses campos vão se estruturando, a partir de relações desiguais de um quantum social determinando, considerando a posição de cada agente, de acordo com o poder que concentra ${ }^{4}$.

Sob este aspecto, o conceito de rede social, mesmo que ainda em fase de sistematização teórico-metodológica, é compreendido como um recurso de grande valor, que pode explicar o potencial mobilizador da sociedade civil e as perspectivas políticas inovadoras, fortalecidas por ações solidárias geradas horizontalmente entre indivíduos e grupos sociais, no interior da sociedade civil, nas esferas de poder dos governos etc. Isso possibilita a compreensão dos desafios da construção de uma cidadania democrática, inserida na era da globalização. Enfatiza-se, então, que o conceito de redes sociais é oportuno, não só por centrar seu foco na análise em atores sociais fixos a partir de determinadas posições ou status, mas, principalmente, na relação propriamente dita. $\mathrm{O}$ valor básico das ações sociais concentra-se não nas preferências ou interesses dos atores sociais, mas na relação social em si mesma: em sua morfologia, densidade, intensidade e sentido ${ }^{5}$.

Portanto, tais conceitos podem ser empregados com base em algumas teorias sociais, necessitando de dados empíricos complementares que sejam capazes de identificar os elos e as relações entre os indivíduos. Para isso, uma proposta teórico-metodológica que contemple demandas de pesquisas e a análise de redes sociais pode ser aplicada em estudos com diferentes situações e questões sociais ${ }^{6}$.

A partir dessas considerações, o objetivo deste artigo foi apresentar a análise de redes sociais como uma proposta de metodologia de pesquisa em saúde e na enfermagem, pontuando conceitos e trazendo alguns possíveis exemplos de aplicação dessa metodologia.

\section{A Metodologia de Análise de Redes SocIAIS}

A análise de redes estabelece uma nova proposta para os estudos que envolvem a estrutura social. No estudo de comportamentos e opiniões dos indivíduos, é preciso identificar as estruturas nas quais os elos (indivíduos) estão inseridos. A análise não recai apenas em atributos individuais (classe, sexo, idade, gênero), mas no conjunto de interações que os indivíduos estabelecem uns com os outros. A estrutura é vista como uma rede de relações e de limitações, que recai sobre as escolhas, orientações, comportamentos e opiniões dos indivíduos ${ }^{6}$.

Por meio da análise de redes, é possível entender a sua estrutura, cuja forma é explicativa para o estudo desses fenômenos. Seu objetivo é demonstrar que a análise de uma díade - interação entre duas pessoas só tem sentido quando em conjunto com outras tantas díades da rede, já que a posição estrutural destas díades tem efeitos sobre a forma da rede, seu conteúdo e sua função. A função de uma relação dependerá da posição estrutural dos elos (representado por um indivíduo, uma organização, por exemplo), o mesmo ocorrendo com o status e o papel do ator. Importante destacar que a rede não se limita apenas à soma de relações e, sendo assim, sua forma exerce influência sobre cada relação ${ }^{6}$.

A análise de rede social é uma ferramenta que possibilita ao pesquisador conhecer as interações entre quaisquer grupos de indivíduos, preferencialmente, através de dados qualitativos. Como essa metodologia requer informações qualitativas, tendo em vista suas próprias características, é preciso seguir algumas técnicas fundamentais, que permitam ordenar as informações geradas pelas interações entre os indivíduos, de modo que tais interações possam ser representadas em um gráfico ou rede?

As redes (ou gráficos) constituem importante ferramenta para representar as interações entre os indivíduos ou grupo de indivíduos. Porém, nem sempre é suficiente representá-los graficamente para estabelecer uma análise mais profunda de cada indivíduo dentro da rede. Somente as ferramentas estatísticas habituais não permitem uma análise mais detalhada e profunda sobre a complexidade das interações sociais. Assim, alguns pesquisadores da área de ciências exatas têm desenvolvido ferramentas específicas para a análise de redes, possibilitando criar indicadores que expliquem a estrutura de uma rede, tanto em suas partes como em sua totalidade ${ }^{7,8}$.

Um dos principais indicadores que permite mensurar o potencial de determinados atores, que podem compor uma ou várias redes sociais, é o índice de centralidade. Esse indicador define a posição dos atores e sua relevância para o conjunto das relações constituídas. Dependendo da posição ocupada por um indivíduo na rede, maiores serão suas oportunidades para se conectar dentro desta rede e, como desdobramento, maiores serão as possibilidades de obtenção de prestígio individual e /ou coletivo. A centralidade em uma rede traz a ideia de poder ${ }^{6,9}$.

Indivíduos que possuem mais laços (contatos) podem ter posições mais vantajosas e tais números de laços podem trazer vias alternativas para satisfazer suas necessidades e, consequentemente, são menos dependentes que outros indivíduos. Por possuírem muitos laços, tem acesso a determinados recursos, o que os torna mais hábeis em lançar mão de tantos outros recursos disponíveis na rede ${ }^{10}$. 
Outros indicadores também são utilizados para a análise de redes sociais. A centralidade de informação é um indicador que permite identificar aquele ator que recebe informações vindas de outras partes da rede, tornando-o uma fonte estratégica. A centralidade de intermediação tem a ver com aqueles atores que servem como ponte, facilitando o fluxo da informação. Um indivíduo pode não ter tantos contatos, estabelecer elos fracos (diferentes vínculos, contatos), mas ser importante na mediação de trocas. Essa característica demarca o poder de controlar as informações que circulam na rede, bem como o seu trajeto. Já a centralidade de fluxo analisa os caminhos de contato dos atores, o que amplia a medida de centralidade de intermediação, que identifica apenas o menor caminho entre os atores. $\mathrm{Na}$ centralidade de fluxo, a intermediação é medida pelo volume de fluxo entre eles, o qual passa por caminhos em que o sujeito esteja inserido. E, por fim, a centralidade de proximidade sinaliza a distância entre os atores, o que permite, de certa maneira, a possibilidade de comunicação com muitas pessoas envolvidas em uma rede, com um número mínimo de intermediários ${ }^{11}$.

Outro destaque para a análise de redes sociais são os conceitos de laços fortes e fracos. Os laços fortes permitem que a rede tenha uma identidade comum, permitindo que as relaçóes aí encontradas possuam alto nível de credibilidade e influência. Indivíduos que compartilham de laços fortes estão inseridos num mesmo círculo social e indivíduos que possuem muitos laços fracos são importantes, pois estão conectados com outros tantos indivíduos que ocupam outras redes de relações. Assim, quanto menos laços fracos, menos pontes entre indivíduos e menos inovação e menor será o fluxo da informação na rede como um todo ${ }^{12,13}$.

Portanto, para chegar-se a esses indicadores, é preciso que se elabore um instrumento de coleta de dados (questionários, entrevistas, grupos focais etc.) que possibilite a busca de informações para a construção da rede e, posteriormente, o cálculo dos indicadores. De posse dos dados encontrados, estes são lançados em uma matriz que é encontrada no software Ucinet. Dentro deste programa, o Netdraw é o responsável pelo desenho estrutural da rede, com seus elos e ligações. Com a rede construída, parte-se para o cálculo dos indicadores através do Ucinet, que possibilita uma análise quantitativa dos achados. Outras metodologias qualitativas podem enriquecer o tratamento dos dados complementares, como análise de conteúdo, por exemplo.

\section{A Análise de Redes Soctais nas Pesquisas EM SAÚDE E NA ENFERMAGEM}

Nos estudos em saúde e na enfermagem, a metodologia de análise de redes sociais pode ser abordada em seus aspectos qualitativos e quantitativos. $\mathrm{Na}$ abordagem qualitativa, são investigados os padrões de relacionamentos que são produzidos no contexto em que se desenvolvem, considerando os indivíduos como atores sociais que (re) constroem a realidade, na busca de novos significados, a partir das interações sociais e das especificidades que medeiam o compartilhamento da informação e a construção do conhecimento na rede. Já na abordagem quantitativa, o foco recai sobre os padrões de relacionamento, ressaltando a objetividade das relações. Isso possibilita o mapeamento do fluxo da informação, dos padrões de comunicação e a percepção de indivíduos importantes nesse processo ${ }^{14}$.

Sob este aspecto, os estudos que utilizam esta metodologia, por meio do uso de indicadores e sociogramas (as redes estruturais), buscam analisar a relação, por exemplo, entre profissionais de saúde com entidades/organizações de saúde, através dos laços sociais que a relação enseja, dentro de um processo mais amplo que se inicia, em muitos casos, fora do sistema de saúde e que vai permeando a relação na esfera pública e privada. Como consequência, tais relações envolvem ações que ultrapassam as demandas sanitárias, indo além do campo da saúde e da comunidade local ${ }^{9}$.

A análise de redes sociais emerge como um importante instrumento de investigação de ações transversais para o planejamento social, que perpassa por diversas realidades. Esta metodologia, no campo da saúde, possibilita, por meio de seus resultados, o planejamento de ações públicas no setor sanitário, pois contribui com indicadores que levam em conta a participação social e as entidades /organizações que possuem uma relação mais próxima com populações mais vulneráveis?

Tais ações podem ser de fundamental importância em locais onde se apresentam graves problemas de proliferação de doenças e mortalidade materno-infantil, por exemplo, já que as pesquisas sociais têm apontado algumas causas determinantes. Essas podem ser evidenciadas pela desarticulação e desorganização de ações entre os serviços e as necessidades de saúde de indivíduos e coletividades (mediante redes de solidariedade) ${ }^{9}$.

Outra possibilidade encontrada no uso dessa metodologia, em relação ao trabalho em saúde, tem a ver com a trama de interações entre profissionais de saúde, gestores, usuários, com sistema de saúde e o cotidiano da vida. Estas interações favorecem a democratização das informações, que estimulam a participação social na saúde, tanto no que se refere às políticas, quanto no que é previsto pelo sistema público de saúde. Essa metodologia possibilita identificar a troca de informações entre os atores envolvidos, bem como o convívio das pessoas com seus círculos e redes sociais, que pode ser descrito como diferentes campos de sociabilidade que, ao se entrecruzarem, podem ampliar o olhar para as práticas em saúde ${ }^{15}$. 
Portanto, os estudos, que utilizam essa metodologia na saúde, procuram identificar o que circula nas interações sociais a favor da manutenção dos vínculos, do reconhecimento mútuo entre os atores envolvidos e as transformações coletivas que ganham expressividade a partir do movimento incessante da tríade dar - receber - retribuir ${ }^{16,17}$.

\section{ConClusão}

A metodologia de análise de redes sociais oferece uma quantidade considerável de pesquisas na saúde e na enfermagem, principalmente quando se combinam as abordagens qualitativas e quantitativas.

No planejamento em saúde, os achados proporcionados pelo uso desta metodologia traz uma diversidade de possibilidades e ações que identificam os atores principais, estes envolvidos em processos de mediação do conhecimento e fluxo das informações, bem como os laços que são construídos e seus desdobramentos das redes sociais.

A análise de redes, pensando nas políticas públicas em saúde, também possibilita a identificação de problemas e oportunidades, estimando alguns parâmetros e encontrando soluções para obtenção no sucesso de aplicação de uma determinada ação dentro de um determinado contexto. Além disso, possibilitam um escaneamento das interações e das redes informais que são construídas, o que permite identificar estratégias e alternativas desenvolvidas entre indivíduos e coletividades, para o contorno de um problema que, em muitos casos, não são considerados e contemplados nas políticas públicas em saúde, como uma ação capaz de mudanças da realidade.

\section{REFERÊNCIAS}

1.Marteleto RM. Redes sociais, mediação e apropriação de informações: situando campos, objetos e conceitos na pesquisa em Ciência da Informação. Ciência da Informação. 2010; 3 (1):27-46.

2. Tomaél MI, Marteleto RM. Redes sociais: posições dos atores no fluxo da informação. Encontros Bibli: revista eletrônica de biblioteconomia e ciência da informação (Florianópolis). 2007; 75-91.

3.Bourdieu P. O capital social: notas provisórias. In:
Bourdieu. Escritos da educação. Petrópolis (RJ): Ed. Vozes; 2007. p 67-9.

4.Marteleto RM, Silva ABO. Redes e capital social: o enfoque da informação para o desenvolvimento local. Ciência da Informação. 2004; 33 (3):41-9.

5.Cordeiro J. Redes sociais e saúde. REDES - Revista hispana para el análisis de redes sociales. 2007; 12 (10):1-17. 6.Marteleto RM. Análise de redes sociais: aplicação nos estudos de transferência da informação. Ciência da Informação. 2001; 30:71-81.

7.Alejandro VAO, Norman AG. Manual introdutório à análise de redes sociais. Portugal $(\mathrm{Pt})$ : Toluca: Universidad Autónoma del Estado de México; 2006.

8.Bacallao-Pino LM. Recursos interactivos y redes sociales en la información sobre salud sexual y reproductiva en la prensa cubana: la sección sexo sentido, del diario Juventud Rebelde. Rev cuba inf cienc salud. 2015; 26 (2):94-106. 9.Silveira PHM. A perspectiva de redes sociais para formação de vínculos entre Agentes Comunitários de Saúde (ACS). Sociedade em Debate. 2010; 16 (2):163-90.

10.Hanneman RA, Riddle M. Introduction to social network methods. Riverside (CA): University of Califórnia; 2005.

11.Tomaél MI, Marteleto RM. Redes sociais: posições dos atores no fluxo da informação. R Eletr Bibliotecon Ci Inf. 2006; (esp.):75-91.

12.Kaufman D. A força dos laços fracos de Mark Granovetter no ambiente do ciberespaço. Galaxia. 2012; 23:207-18.

13.Portugal S, Nogueira C, Hespanha P. As teias que a doença tece: a análise das redes sociais no cuidado da doença mental. Dados. 2014; 57:935-68.

14.Marteleto RM, Tomaél MI. A metodologia de análise de redes sociais (ARS). In: Valentim MLP. Métodos qualitativos de pesquisa em ciência da Informação. São Paulo: Polis; 2005. p. 81-100.

15.Pinheiro RL. A prática do agente comunitário de saúde com redes sociais na estratégia saúde da família [dissertação de mestrado]. Ribeirão Preto (SP): Universidade de São Paulo; 2012.

16.Lacerda A. Redes de apoio social no sistema da dádiva: um novo olhar sobre a integralidade do cuidado no cotidiano de trabalho do agente comunitário de saúde [tese de doutorado]. Rio de Janeiro: Escola Nacional de Saúde Pública Sérgio Arouca; 2010.

17.Pinheiro RL, Guanaes-Lorenzi C. funções do agente comunitário de saúde no trabalho com redes sociais. Estud Psicol. 2014; 19:48-57. 